\title{
THE COMPETITIVE EDGE OF AN INVADING SPECIALIST
}

\author{
Thomas BøHN ${ }^{1}$ And Per-Arne Amundsen \\ Norwegian College of Fisheries Science, University of Troms $\phi$, N-9037 Troms $\phi$, Norway
}

\begin{abstract}
Introduced species represent major threats to native and natural biodiversity. On the other hand, biologists may increase the understanding of ecological interactions by following communities during establishment of exotic species. Accordingly, feeding ecology and habitat use were studied in native whitefish (Coregonus lavaretus) and recently invading vendace (C. albula) in two lake localities situated $50 \mathrm{~km}$ apart within the subarctic Pasvik River system, northern Norway and Russia. Whitefish originally dominated the native fish communities of both lakes. The recent invasion and successive downstream expansion of vendace allowed comparisons between two sites: one in which the influence of the new potential competitor on the native fish species was weak, and one in which the influence was strong. In the downstream lake vendace was recorded for the first time at the time of the study, and only in small numbers, whereas in the upstream lake vendace had established a high population density and was the dominant fish species in the pelagic zone. No vertical segregation in pelagic habitat use was found between the two fish species in either lake. In the downstream lake both whitefish and vendace fed exclusively on zooplankton and had almost identical diets. In the upstream lake, in contrast, whitefish fed predominantly on zoobenthos and surface insects, while vendace fed mainly on zooplankton. Thus, the strong presence of vendace as a specialized planktivore reduced the availability of zooplankton as prey for the more generalist whitefish. The food segregation between the two fish species in the upstream lake was apparently interactive and caused by a strong asymmetrical competition for zooplankton, vendace being the superior species. The ecological consequences (including reduced zooplankton size and species diversity, alteration of the pelagic food web, and eutrofication as a possible cascading effect on the primary production) of the vendace invasion in the Pasvik watercourse are considerable, even after a few years, and are likely to proceed and intensify in the future.
\end{abstract}

Key words: asymmetric competition; Coregonus; diet overlap; fish invasion; interactive segregation; invasive species; Pasvik River system (northern Norway and Russia); pelagic zone, feeding ecology and habitat use; resource partitioning; species invasion.

\section{INTRODUCTION}

Interspecific competition is the central mechanism that leads to resource partitioning (Schoener 1974, Werner 1984), and may be identified when species alter their resource utilization between allopatric and sympatric situations (Nilsson 1967, Werner 1986, Wootton 1990). When an exotic species is invading, both allopatric and sympatric situations may be found in adjacent localities, and knowledge of community pattern and processes (e.g., resource partitioning, interactive segregation, and competition) can be extracted (Simberloff 1981, Pimm 1989, Ross 1991). The adverse effects that frequently follow introductions and invasions (Ross 1991) have, however, been met by international agreements aimed at reducing the spread of exotic species (WRI/IUCN/UNEP 1992). Thus, when new introductions occur accidentally, strong effort should be made to extract as much knowledge as possible from the event (Evans et al. 1987). In addition, there are very few detailed studies of introduced trophic

Manuscript received 6 December 1999; revised 29 May 2000; accepted 10 July 2000; final version received 16 October 2000.

\footnotetext{
${ }^{1}$ E-mail: thomasb@nfh.uit.no
}

specialists compared to studies of introduced trophic generalists (Ebenhard 1988).

Two species compete when they negatively affect each other by consuming, or controlling access to, a limited resource (Keddy 1989). Low resource availability and high overlap in fundamental niches make competition more likely (Giller 1984, Wootton 1990). Interspecific competition may, for one or more of the species involved, lead to altered resource utilization. Under intensive competition between ecologically similar species, one of the species is expected to be excluded from the overlapping part of the resource axis, i.e., competitive exclusion occurs (Gause 1934, Hardin 1960). Hence, coexistence of two species in time is assumed to depend upon resource partitioning along at least one resource axis or niche dimension (Schoener 1974, 1986, Ross 1986).

The present study is related to a recent invasion of vendace (Coregonus albula (L.)), a highly specialized zooplanktivore fish species (Hamrin 1983, Viljanen 1983, Kankaala et al. 1990), into the subarctic Pasvik River system (Amundsen et al. 1999). The natural distribution of vendace does not include northern Fennoscandia, but in the 1960s the species was translocated 
and introduced into tributaries of Lake Inari, Northern Finland (Mutenia and Salonen 1992). In Lake Inari, vendace reached a high population density during the second half of the 1980s (Mutenia and Ahonen 1990), then subsequently migrated downstream into the Pasvik watercourse, where it was recorded for the first time in 1989 (Amundsen et al. 1999). The pelagic fish communities in the lakes of the Pasvik watercourse were originally dominated by whitefish (Coregonus lavaretus (L.)), a species closely related to vendace, but less efficient as a zooplanktivore (Svärdson 1976). As vendace invaded the upstream part of the watercourse, it replaced whitefish as the dominant fish species in the pelagic zone (Amundsen et al. 1999).

The gradual downstream expansion of vendace in the Pasvik River system facilitated a study of the mechanisms of competition in a large-scale "natural experiment," enabling comparisons of diet and habitat use of an invading specialist with those of the less specialized native species in lakes with different competitive impacts. Different impacts also imply different available resources of zooplankton in the two respective prey communities. Accordingly, two lake localities were investigated for fish and zooplankton;-one upstream in the watercourse where the invading vendace had been prevalent in the pelagic fish community for at least three years, and one downstream where a low abundance of vendace was recorded for the first time at the time of the study. Assuming that the invasion and establishment of a dense vendace population in the upstream lake had led to a strong interspecific competition with whitefish, we hypothesized that this competition would be followed by an interactive segregation in feeding and/or habitat use due to a reduced level of available zooplankton. In the downstream lake, on the other hand, no significant resource competition was expected to have developed due to the recent invasion and low density of vendace. The downstream lake was thus assumed to closely parallel the undisturbed pre-invasion situation, serving as a control locality where the two species would be expected to have similar niches.

\section{Study Area And Fish Communities}

The Pasvik River system originates from Lake Inari $\left(1102 \mathrm{~km}^{2}\right)$ in Finland, runs into Russia and then defines the border between Norway and Russia for a length of $\sim 120 \mathrm{~km}$ (Fig. 1). The Norwegian-Russian part of the river system has a total area of $142 \mathrm{~km}^{2}$, a catchment area of $18404 \mathrm{~km}^{2}$, and a mean annual water flow of $\sim 175 \mathrm{~m}^{3} / \mathrm{s}$. There are altogether seven water impoundments in the watercourse. Most rapids and waterfalls have disappeared, and today the river system is dominated by lakes and reservoirs. The water-level fluctuations are small, usually $<80 \mathrm{~cm}$. The ice-free season in the lakes and reservoirs lasts from late May or early June to the end of October or early November. The lakes and reservoirs in the watercourse are oligotrophic with some humic impact; the Secchi depth ranges from
2 to $6 \mathrm{~m}$. The geology in the region is dominated by bedrock, mainly containing gneiss. The catchment area is dominated by birch- and pinewoods intermingled with stretches of bogs. Annual mean air temperature is low $\left(-3^{\circ} \mathrm{C}\right)$ and minimum and maximum monthly mean temperatures are $-13.5^{\circ} \mathrm{C}$ and $+14.0^{\circ} \mathrm{C}$, respectively. The precipitation in the area is low, with an annual mean of $358 \mathrm{~mm}$.

Two different lake localities, situated about $50 \mathrm{~km}$ apart in the watercourse, were investigated: Ruskebukta in the upstream part, and Skrukkebukta downstream (Fig. 1). Both basins are located adjacent to the main path of the Pasvik River system, and have negligible water flow. Ruskebukta $\left(69^{\circ} 13^{\prime} \mathrm{N}, 29^{\circ} 14^{\prime} \mathrm{E} ; 52 \mathrm{~m}\right.$ above sea level [a.s.l.]) has an area of $5.3 \mathrm{~km}^{2}$ and a maximum depth of $15 \mathrm{~m}$. Skrukkebukta $\left(69^{\circ} 33^{\prime} \mathrm{N}\right.$, $30^{\circ} 7^{\prime} \mathrm{E} ; 21 \mathrm{~m}$ a.s.1.) has an area of $6.6 \mathrm{~km}^{2}$ and a maximum depth of $19 \mathrm{~m}$. The water chemistry of the two lakes is very similar (Table 1).

Altogether, 15 species of fish have been recorded in the Pasvik River system. The two lake localities have similar fish communities with whitefish (Coregonus lavaretus (L). sensu lato), perch (Perca fluviatilis L.), pike (Esox lucius L.), burbot (Lota lota L.), and brown trout (Salmo trutta L.) being the most commonly occurring native species. The whitefish occur as two different morphs, differentiated by the morphology and number of gill rakers, here referred to as densely and sparsely rakered whitefish. The densely rakered whitefish have numerous long and narrowly spaced gill rakers (mean number 33.0), whereas the sparsely rakered form has fewer, shorter and more widely spaced rakers (mean number 23.1) (Amundsen et al. 1999). According to Reshetnikov (1980), the two forms may be referred to as Coregonus lavaretus mediospinatus (densely rakered whitefish) and C. lavaretus pidschian (sparsely rakered), whereas Svärdson $(1957,1979)$ described these forms as two different species, C. lavaretus and C. nasus, respectively. The densely rakered whitefish usually occupy the pelagic zone, feeding predominantly on zooplankton, whereas the sparsely rakered form feeds mainly on zoobenthos in littoral and profundal habitats (Amundsen 1988). Prior to the invasion of vendace, whitefish was the dominant fish species in the pelagic, profundal, and littoral habitats of the lakes and reservoirs in the Pasvik River system. In the pelagic zone, the densely rakered whitefish (hereafter only referred to as whitefish) constituted, on average, $>95 \%$ of the total catches (Amundsen et al. 1999).

\section{Methods Fish}

Fish were sampled in the upstream and downstream lakes during 22-31 June, 10-17 August, and 14-22 September 1993, using pelagic gill nets with bar mesh sizes of $8,10,12.5,15,18.5,22,26$, and $35 \mathrm{~mm}$. The gill nets were $12 \mathrm{~m}$ deep and marked at every $2 \mathrm{~m}$ depth interval to facilitate recording of the capture 


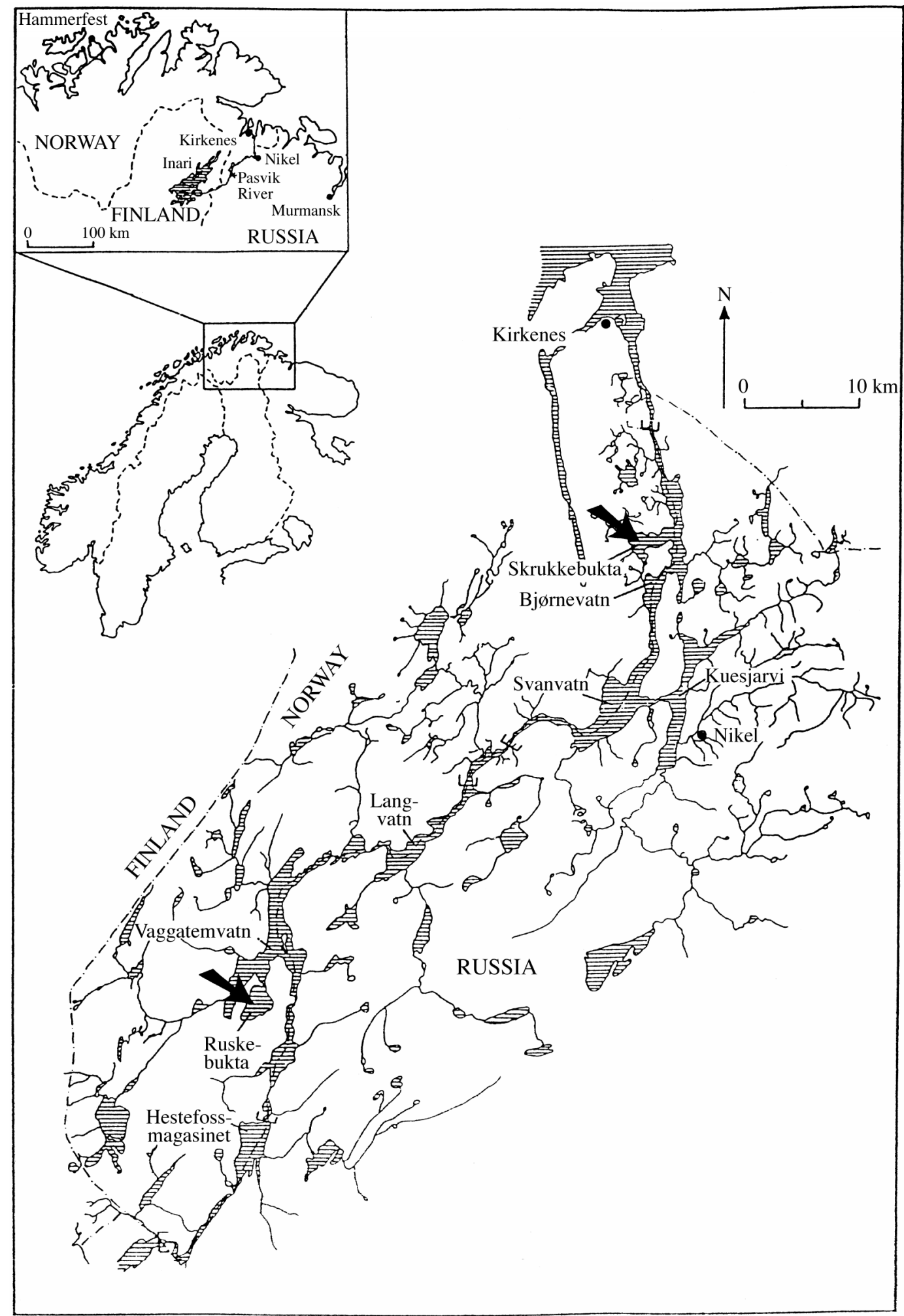

FIG. 1. Map of the Pasvik River system. Arrows show the upstream (Ruskebukta) and downstream (Skrukkebukta) lakes. 
TABLE 1. Limnological data from the lakes studied in the Pasvik River system, northern Norway and Russia.

\begin{tabular}{lccccccccr}
\hline \hline Lake locality $\dagger$ & Date & $\begin{array}{c}\text { Turbid- } \\
\text { ity }\end{array}$ & $\begin{array}{c}\text { Conduc- } \\
\text { tivity } \\
(\mu \mathrm{S} / \mathrm{cm})\end{array}$ & $\mathrm{pH}$ & $\begin{array}{c}\text { Alkali- } \\
\text { nity } \\
\mu \mathrm{mol} / \mathrm{L}\end{array}$ & $\begin{array}{c}\mathrm{Ca} \\
(\mathrm{mg} / \mathrm{L})\end{array}$ & $\begin{array}{c}\mathrm{Na} \\
(\mathrm{mg} / \mathrm{L})\end{array}$ & $\begin{array}{c}\mathrm{Cl} \\
(\mathrm{mg} / \mathrm{L})\end{array}$ & $\begin{array}{r}\mathrm{No}_{3}-\mathrm{N} \\
(\mu \mathrm{L} / \mathrm{L})\end{array}$ \\
\hline Upstream & 30 Jun & 2.10 & 32.6 & 6.83 & 177 & 2.21 & 1.71 & 1.75 & 3 \\
& 8 Sep & 4.60 & 33.5 & 6.43 & 167 & 2.44 & 1.77 & 1.66 & 6 \\
Downstream & 1 Jul & 1.40 & 43.1 & 6.97 & 199 & 2.87 & 2.07 & 1.74 & 12 \\
& 8 Sep & 0.85 & 41.4 & 6.93 & 200 & 3.35 & 1.94 & 1.76 & 8 \\
\hline
\end{tabular}

Source: Data are from Langeland (1993).

$\dagger$ Upstream: Ruskebukta; downstream: Skrukkebukta. See Fig. 1.

depth of each individual fish. Stomach samples were taken from all size classes of vendace $(80-170 \mathrm{~mm}$ fork length) and a subsample of whitefish (80-170 mm length, including $\sim 90 \%$ of the total whitefish sample), and preserved in $96 \%$ ethanol. In the laboratory, stomach samples were analyzed and categorized into 11 different prey groups.

The stomach fullness in volume was determined subjectively on a scale from 0 (empty) to $100 \%$ (full), and the fullness of each diet category was determined in such a way that the sum of all categories equalled the total stomach fullness. The proportion of each diet category was expressed in percentage as prey abundance, $A$ :

$$
A_{i}=100 \times \sum F_{i} / \sum F_{t}
$$

where $F_{i}$ is fullness for diet category $i$ and $F_{\mathrm{t}}$ is the total stomach fullness.

Diet overlap.-Interspecific diet overlap between vendace and whitefish was calculated with Schoener's index (Schoener 1970):

$$
\begin{array}{r}
D=100\left(1-0.5 \times \sum_{i=1}^{n}\left|p_{x, i}-p_{y, i}\right|\right) \\
\quad i=1,2, \ldots, n
\end{array}
$$

where $p_{x, i}=$ the proportion $(0-1)$ of diet category $i$ from the stomach of predator $x, p_{y, i}$ the same for predator $y$, and $n=$ number of diet categories. $D>60$ expresses a significant overlap according to Wallace (1981).

The inter-lake diet overlap (overlap within each fish species, between lakes) was also calculated with Schoener's index:

$$
\begin{aligned}
& D_{\text {vendace }}=100\left(1-0.5 \times \sum_{i=1}^{n}\left|v_{x, i}-v_{y, i}\right|\right) \\
& i=1,2, \ldots, n \\
& D_{\text {whitefish }}=100\left(1-0.5 \times \sum_{i=1}^{n}\left|w_{x, i}-w_{y, i}\right|\right) \\
& i=1,2, \ldots, n
\end{aligned}
$$

where $D=$ inter-lake diet overlap (for vendace and whitefish); $v_{x, i}$ and $w_{x, i}=$ the proportion $(0-1)$ of diet category $i$ from the diets in vendace and whitefish, respectively, in lake $x$; while $v_{y, i}$ and $w_{y, i}=$ the proportion (0-1) of diet category $i$ from the diets in vendace and whitefish, respectively, in lake $y ; n=$ number of diet categories.

Niche width. - The niche width was calculated with Levins index (Levins 1968):

$$
W=1 /\left(\sum_{i=1}^{n} p_{i}^{2}\right) \quad i=1,2, \ldots, n
$$

where $W=$ niche width, $p_{i}=$ the proportion $(0-1)$ of prey category $i$, and $n=$ the number of prey categories.

\section{Zooplankton}

Zooplankton was sampled using a 30-L Schindlerbox (Schindler 1969) with a mesh size of $65 \mu \mathrm{m}$, and fixed with Lugol solution. Two parallel samples were taken at $1,3,5,7,9$, and $12 \mathrm{~m}$ of depth. In the laboratory all crustacean species from the zooplankton samples and stomach samples of vendace and whitefish were identified and counted. Five cladoceran species, Bosmina longirostris Müller, B. longispina Leydig, Daphnia cristata Sars, Holopedium gibberum Zaddach, and Leptodora kindtii Focke, and four copepods, Cyclops scutifer Sars, Eudiaptomus graciloides Liljeborg, Heterocope appendiculata Sars and Megacyclops gigas Claus, were found.

Body lengths (distance from the top of the head to the base of the caudal spine) were measured for the four most abundant cladoceran species (B. longirostris, B. longispina, D. cristata, and H. gibberum), both from plankton and stomach samples. A binocular with $50 \times$ magnification was used for counting and measuring.

The biomass of the cladoceran zooplankton was estimated using the following regression lines between body length in millimeters, $L$, and dry mass in micrograms, $M$ :

Bosmina longirostris: $\quad \ln M=3.093+2.595 \times \ln L$ B. longispina: $\quad \ln M=3.093+2.595 \times \ln L$ Daphnia cristata: $\quad \ln M=1.600+2.840 \times \ln L$ Holopedium gibberum: $\ln M=3.186+3.219 \times \ln L$.

(Bottrell et al. 1976 [for D. cristata], Langeland 1982 [for B. longirostris, B. longispina, and H. gibberum]). 
TABLE 2. Numbers of vendace and whitefish ("Wh. fish") caught in the pelagic zone of the upstream and downstream lakes throughout the 1993 sampling season.

\begin{tabular}{|c|c|c|c|c|c|c|c|c|}
\hline \multirow[b]{2}{*}{ Location } & \multicolumn{2}{|l|}{ June } & \multicolumn{2}{|c|}{ August } & \multicolumn{2}{|c|}{ September } & \multicolumn{2}{|l|}{ Total } \\
\hline & Vendace & $\begin{array}{l}\text { Wh. } \\
\text { fish }\end{array}$ & Vendace & $\begin{array}{l}\text { Wh. } \\
\text { fish }\end{array}$ & Vendace & $\begin{array}{l}\text { Wh. } \\
\text { fish }\end{array}$ & Vendace & $\begin{array}{l}\text { Wh. } \\
\text { fish }\end{array}$ \\
\hline Upstream lake & $132(46 \%)$ & 157 & $99(49 \%)$ & 104 & $213(79 \%)$ & 55 & $444(58 \%)$ & 316 \\
\hline Downstream lake & $1(2 \%)$ & 53 & $36(21 \%)$ & 139 & $43(15 \%)$ & 238 & $80(16 \%)$ & 430 \\
\hline
\end{tabular}

Note: The relative contribution of vendace is given in parenthesis.

The biomass of C. scutifer and E. graciloides was calculated from the number of individuals in each developmental (copepodite) stage and existing data on mean dry masses of each stage (Christensen 1994). Nauplii larvae were not included.

Leptodora kindtii, Megacyclops gigas, and Heterocope appendiculata were rare both in the zooplankton samples and in the stomach samples, and were not included in the biomass estimates.

The biomass of edible zooplankton was calculated by defining edible cladocerans as specimens larger (in length) than the lower 5\% quantile found in the stomachs of vendace and whitefish. Thereby, Bosmina spp.

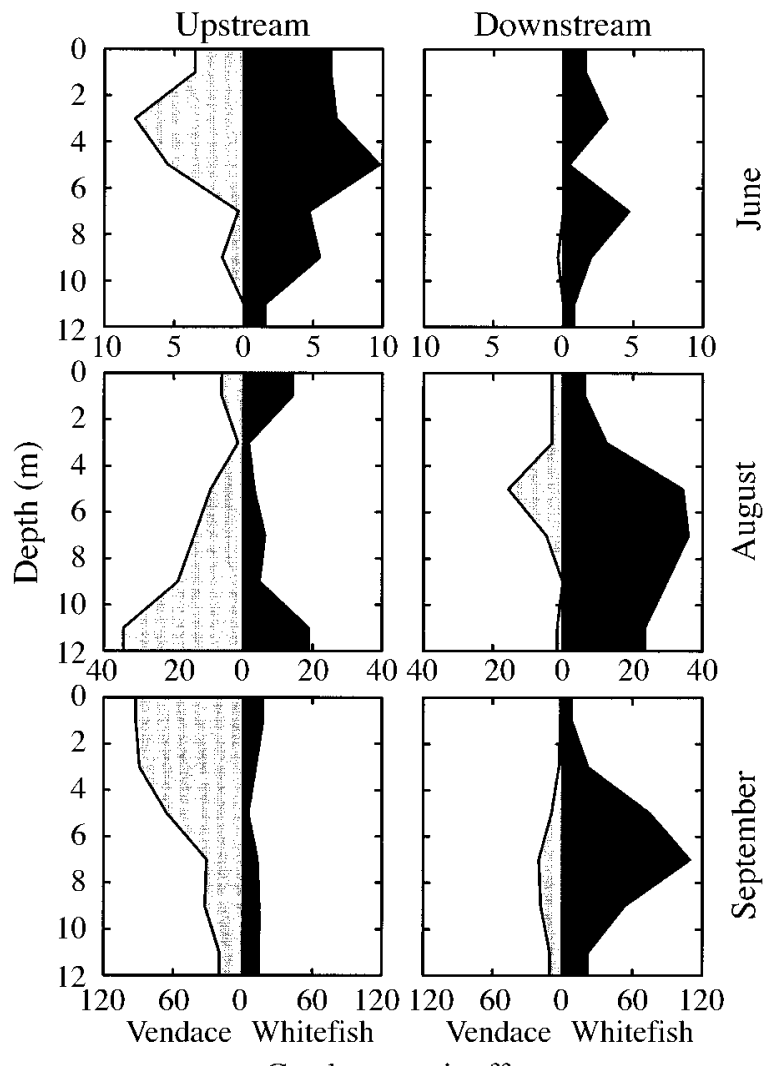

Catch per unit effort

FIG. 2. Vertical distribution of vendace and whitefish from the upstream and downstream lakes through the season. Data are from catches per unit effort (number of fish caught in gillnets per $100 \mathrm{~m}^{2}$ per night) at different depths $(0-12$ $\mathrm{m})$.
$>0.315 \mathrm{~mm}$ and $D$. cristata $>0.433 \mathrm{~mm}$ were considered edible for the vendace, and Bosmina spp. $>0.335$ $\mathrm{mm}$ and D. cristata $>0.433 \mathrm{~mm}$ for the whitefish. All sizes of $H$. gibberum and copepods were considered edible.

\section{RESUlts}

\section{Species composition of fish in the pelagic habitat}

Vendace and (densely rakered) whitefish dominated the pelagic fish samples. Other species (perch, pike, brown trout, and sparsely rakered whitefish) made up only $3.9 \%$ and $1.5 \%$ of the total catches in the upstream and downstream lakes, respectively. These other fish species are not considered further. Vendace dominated in the upstream lake with $58 \%$ of the catches over the season (Table 2). In the downstream lake, only one vendace was caught in June, but 79 individuals caught in August and September made vendace contribute 16\% to the total catches.

There was no apparent segregation in depth distribution of vendace and whitefish in the two lakes (Fig. 2 ). The total catch per unit effort (number of vendace and whitefish per $100-\mathrm{m}^{2}$ gillnet per night) increased strongly through the season in both lakes $(8.9,22$, and 67 in June, August, and September, respectively, in the upstream lake, compared to 2.1,28, and 59 in the downstream lake). The estimated total density of fish was slightly higher, $10 \%$ on average, in the upstream lake.

\section{Diet}

Stomach fullness.-In the upstream lake, vendace had a mean stomach fullness of $\sim 10 \%$ through the season, whereas whitefish had $18 \%$ stomach fullness in June and $36-37 \%$ in August and September. Thus, the whitefish had more stomach contents than vendace. However, the amount of zooplankton was higher through the season in the vendace diet compared to the whitefish (Fig. 3).

In the downstream lake, vendace had a stomach fullness of $66-70 \%$ in August and September, whereas whitefish had a stomach fullness of $16 \%$ in June and $\sim 55 \%$ in August and September. Almost all stomach contents were zooplankton for both fish species (Fig. 3).

Diet composition in different depths.-Zooplankton formed $\sim 80 \%$ of the vendace diet in the upstream lake (Fig. 4). In August, vendace caught closer to the surface 
FIG. 3. Level of total stomach fullness (mean and $1 \mathrm{SE}$ ) for vendace (hatched and black bars) and whitefish (open and gray bars) in the upstream and downstream lakes throughout the sampling season. The black and gray shading represents the zooplankton contribution in the diets. Levels of significance for differences between the species are denoted above the bars $(* P<0.05, * * P<0.01, * * * P \leq 0.001, \mathrm{NS}=$ not significant at $P<0.05$; Kruskal-Wallis test).
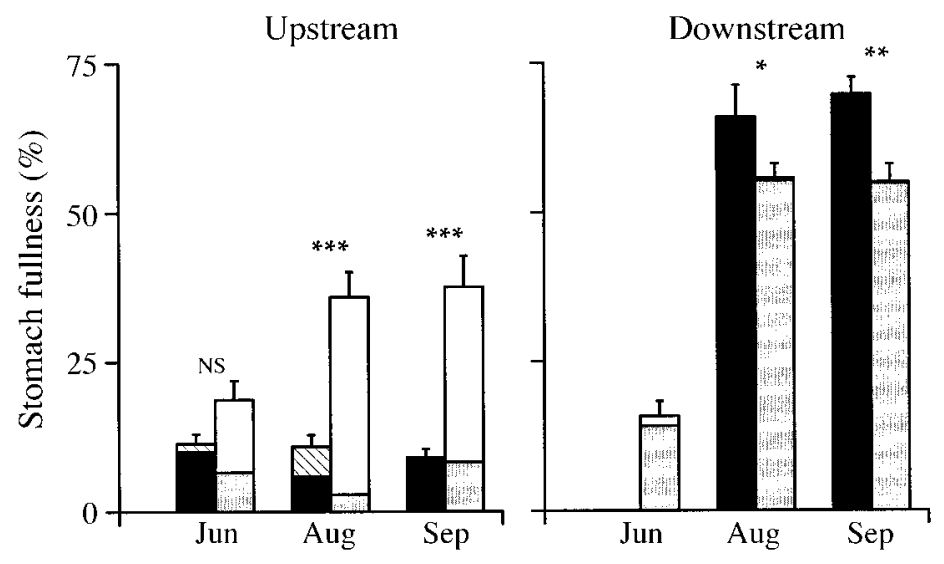

Upstream
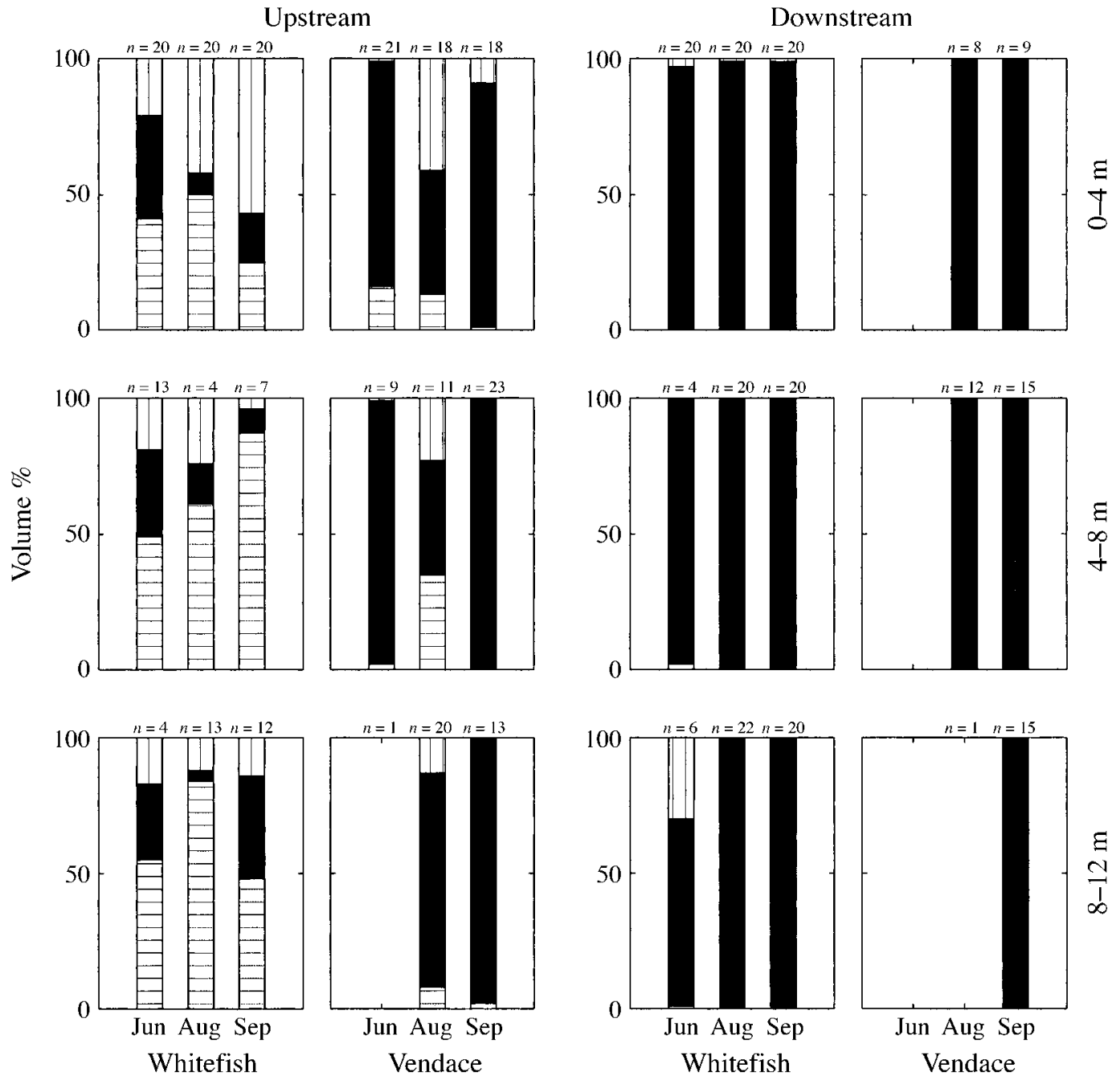

FIG. 4. Relative contribution of surface insects (vertical hatching), zooplankton (solid bars), and zoobenthos (horizontal hatching) in the diet of vendace and whitefish caught at different depths in the upstream and downstream lakes. Numbers of fish are given; samples with $n<4$ fish were not included. 

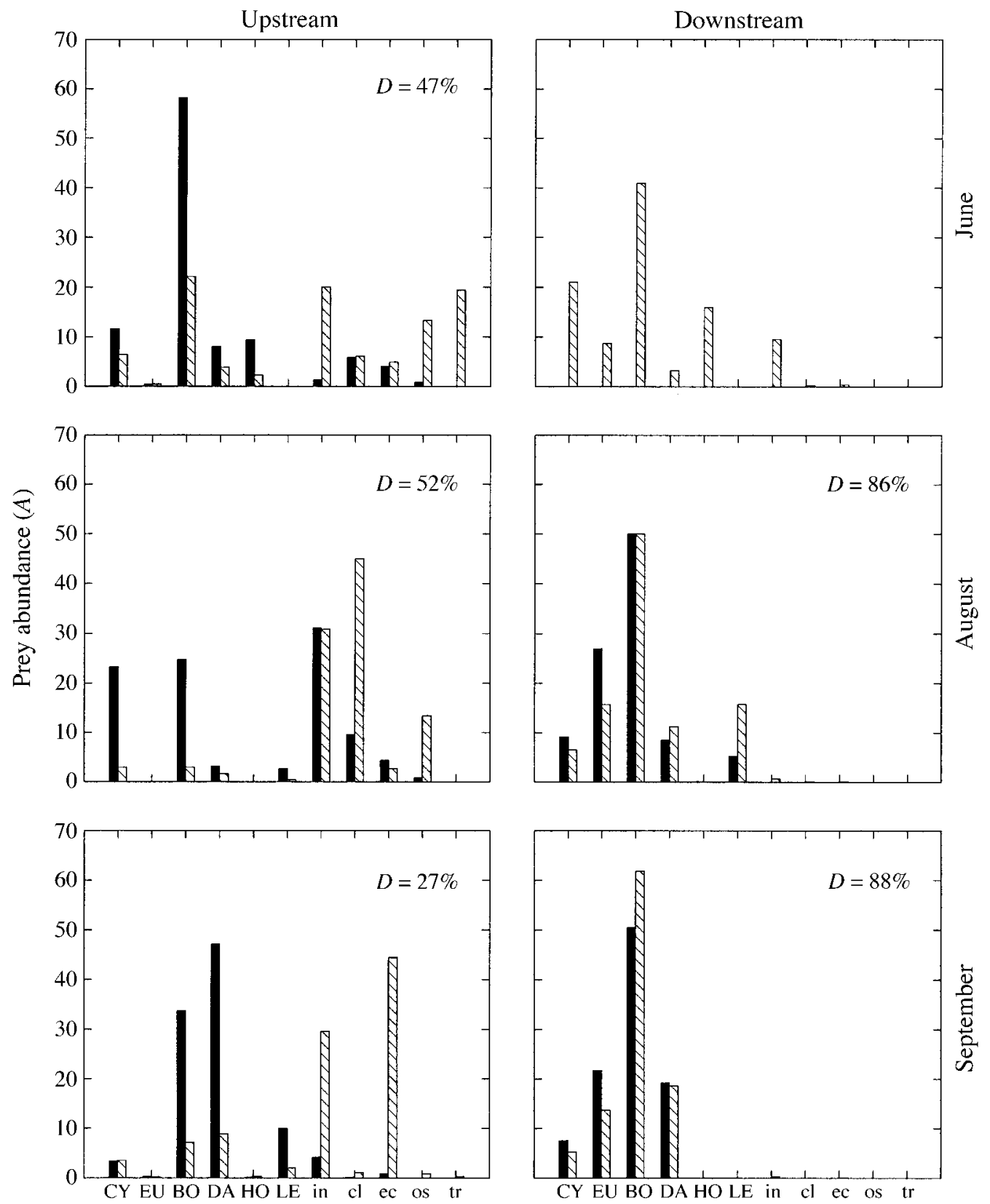

FIG. 5. Diet composition of vendace (solid bars) and whitefish (hatched bars) from the pelagic zone (0-12 m) of the upstream and downstream lakes through the sampling season. The diet overlap $(D)$ between the two species is also given. Abbreviations for zooplankton prey are in capital letters, and other categories are in lowercase letters: CY $=C y c l o p s$, EU $=$ Eudiaptomus, $\mathrm{BO}=$ Bosmina, $\mathrm{DA}=$ Daphnia, $\mathrm{HO}=$ Holopedium, $\mathrm{LE}=$ Leptodora, in $=$ surface insects, $\mathrm{cl}=\mathrm{chironomid}$ larvae, ec = Eurycercus, os = Ostracoda, and tr = Trichoptera .

had an increased amount of surface insects in their diet. Whitefish from the upstream lake had $\sim 20 \%$ zooplankton in their diet. The amount of zoobenthos, which predominated in the whitefish diet, increased towards the bottom while surface insects increased towards the surface.

In the downstream lake, zooplankton predominated in the diet at all depths for both fish species. Some surface insects were found in the whitefish diet near the bottom and near the surface in June (Fig. 4). In general, the coarse-grained diet of vendace and whitefish caught at different depths was similar, justifying a more detailed diet analysis based on pooled samples from the whole pelagic zone $(0-12 \mathrm{~m})$.

Diet composition and overlap (pooled samples 0-12 $m$ ).--In the upstream lake, the zooplankton species Bosmina spp., Daphnia cristata, and Cyclops scutifer were the most important prey of vendace (Fig. 5). Small 
TABLE 3. Niche width for vendace and whitefish in the upstream and downstream lakes through the 1993 season.

\begin{tabular}{lccccc}
\hline \hline \multirow{2}{*}{1993} & \multicolumn{2}{c}{ Upstream lake } & & \multicolumn{2}{c}{ Downstream lake } \\
\cline { 2 - 3 } \cline { 5 - 6 } \cline { 5 - 6 } & Vendance & Whitefish & & Vendace & Whitefish \\
\hline June & 2.7 & 6.4 & & $\ldots$ & 3.9 \\
Sugust & 4.5 & 3.1 & & 2.9 & 3.1 \\
September & 2.9 & 3.3 & & 2.9 & 2.3 \\
\hline
\end{tabular}

Note: Niche width was calculated with the Levins index (Levins 1968).

proportions of surface insects and zoobenthos such as chironomid larvae and Eurycercus lamellatus were also found in all seasons, and in August the non-zooplankton part of the vendace diet formed as much as 50\% of the total diet. Whitefish in the upstream lake were mainly feeding on caddisfly larvae and Bosmina spp. in June, chironomid larvae in August, and Eurycercus in September. Surface insects were important in all seasons. The diet overlap between vendace and whitefish in the upstream lake was $\sim 50 \%$ in June and August, falling to $27 \%$ in September (Fig. 5).

In the downstream lake, both vendace and whitefish fed almost exclusively on zooplankton, with Bosmina spp., Eudiaptomus graciloides, D. cristata, and C. scutifer being the most important prey categories. The diets of the two fish species were highly similar, overlapping $86 \%$ in August and $88 \%$ in September (Fig. 5).

Niche width.-In the upstream lake vendace had a narrow niche width in June and September, but a markedly wider niche in August (Table 3) when other prey categories than zooplankton also were included in the diet (cf. Fig. 5). The whitefish had its widest niche in June, when it included zooplankton in addition to the dominating benthic prey categories.

In the downstream lake the niche width of both species was low and fairly constant through the season (Table 3).

Inter-lake diet overlap.-The inter-lake diet overlap of vendace was markedly higher than the comparable

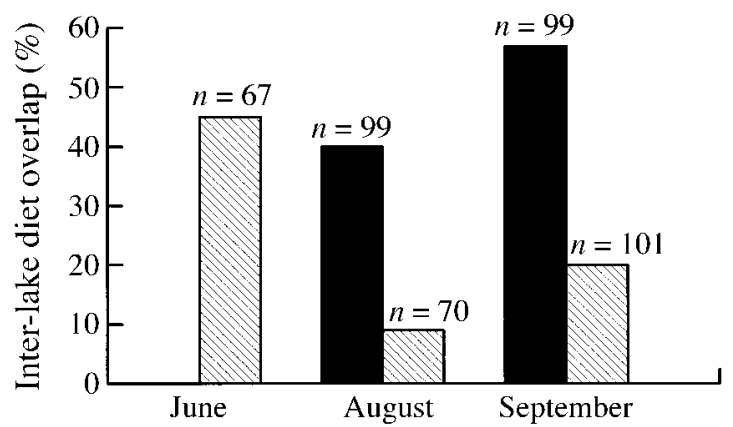

FIG. 6. Inter-lake diet overlap between the upstream and downstream lakes for whitefish (hatched bars) and vendace (solid bars). The numbers of stomachs used for calculations (sum of both lakes) are given; data are from all depths $(0-$ $12 \mathrm{~m})$.
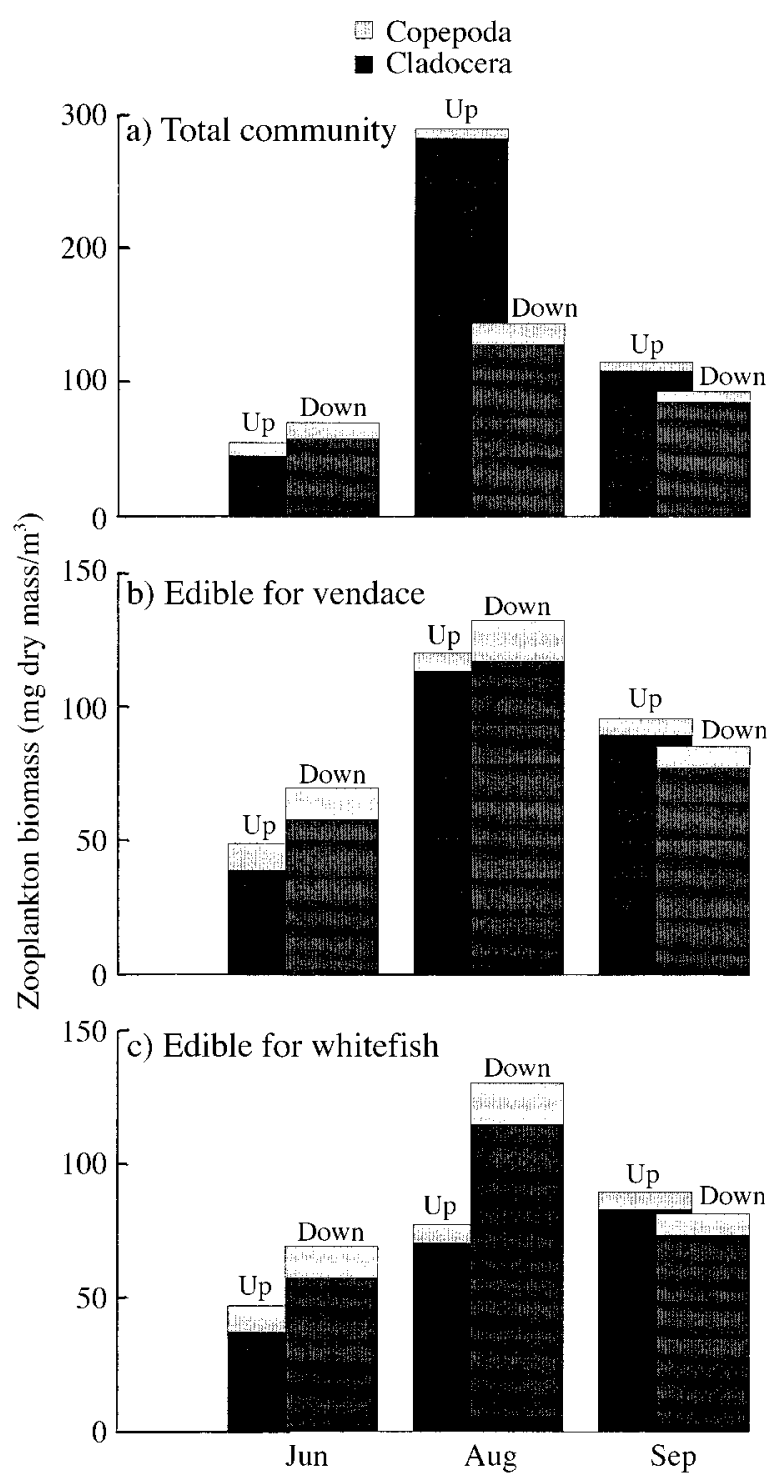

FIG. 7. Biomass of zooplankton (separated into cladocerans and copepods) from the upstream and downstream lakes throughout the season: (a) the total community; (b) the edible zooplankton for vendace; and (c) the edible zooplankton for whitefish (see Methods: Zooplankton for explanation). Data are pooled from all depths $(0-12 \mathrm{~m})$.

overlap for whitefish (Fig. 6). The difference in interlake overlap between vendace and whitefish was 31 and 37 percentage points in August and September, respectively. A relatively high inter-lake diet overlap was found for the whitefish in June, but since vendace was absent in the downstream lake, no comparison could be made.

Zooplankton biomass.-The biomass of zooplankton in the two lakes consisted mainly of cladoceran species. In August the biomass in the upstream lake was more than twice the amount in the downstream lake (Fig. 7a), but most of this zooplankton consisted of very small individuals of Bosmina longirostris that were not 
edible for the fish (see Methods: Zooplankton). Thus, the biomass of zooplankton edible for vendace was much smaller than the total zooplankton biomass in the upstream lake in August, resulting in a lower level of edible zooplankton in the upstream lake compared to the downstream lake in June and August, but not in September (Fig. 7b). The biomass of zooplankton edible for whitefish was even more reduced in the upstream lake in August, resulting in a much lower quantity of edible zooplankton in August (Fig. 7c).

\section{Discussion}

The introduction of vendace into the headwaters of the Pasvik watercourse opened the possibility to study the ecological consequences of an invading specialist into a subarctic fish community. The established population of vendace is the northernmost in the world (Amundsen et al. 1999), and the species is potentially meeting a physiologically extreme environment that could have limited the growth of the population. Nevertheless, the vendace has over a few years increased considerably in density (Amundsen et al. 1999) and has adopted the role of a key species in the pelagic community, similar to its role in the natural distribution area (Svärdson 1976). The specialized food selection and lack of ontogenetic niche shifts make this species a strong competitor for zooplankton resources (Auvinen 1988, Helminen and Sarvala 1994). Vendace populations often reach very high densities (Hamrin and Persson 1986, Sandlund et al. 1991) and may cause strong effects on the food web by altering the structure of the zooplankton community (Kankaala et al. 1990, Rudstam et al. 1993), and even transferring cascading effects to the primary production (Bøhn and Amundsen 1998; cf. Shapiro 1980, Carpenter et al. 1985, McQueen et al. 1989).

Zooplankton generally respond more markedly to predation in small basins (Gliwicz and Pijanowska 1989). Thus, the zooplankton communities of the relatively small and shallow lakes in the Pasvik River system should be vulnerable to changes. In the upstream part of the watercourse, the invasion and strong expansion of vendace has led to a shift in both zooplankton size and species composition. The smallest zooplankton species in the community (Bosmina longirostris) has replaced larger cladocerans and has become the dominant species in the upstream lake $(\mathrm{B} \varnothing \mathrm{hn}$ and Amundsen 1998). Similarly, the three most numerous cladoceran species were all significantly smaller upstream compared to downstream during mid-summer (Bøhn and Amundsen 1998). Therefore, the zooplankton community in the upstream lake seems to have been overexploited and depleted as a food resource for fish. This is contradicted by the results on the total biomass of zooplankton in the two lakes. The biomass upstream was more than double that of the biomass downstream in mid-summer (Fig. 7a). However, most of this biomass was from the very small B. longirostris, which had a strong negative preferability as prey in the upstream lake in the same period ( $\mathrm{B} \varnothing \mathrm{hn}$ and Amundsen 1998), indicating that these specimens were not edible for the fish. Using a conservative estimate for the part of the zooplankton that was edible (see Methods: Zooplankton), the findings on biomass were reversed with least edible zooplankton found in the upstream lake (Fig. 7b and c). Especially for the less specialized zooplanktivore whitefish the amount of edible zooplankton was considerably lower in the upstream lake. Furthermore, even within the edible part of the zooplankton, smaller individuals of a particular species (as found in the upstream lake) are always less valuable as food than larger individuals (as found downstream). Thus, the upstream lake clearly had a more limited access to zooplankton as food for the two competitors. This was also supported by the very low levels of stomach fullness in vendace from the upstream compared to the downstream lake (Fig. 3). Vendace is described as the most specialized zooplanktivore fish in Scandinavia (Svärdson 1976), and even after having depleted the zooplankton community of the upstream lake vendace still maintained its specialization on zooplankton. About $80 \%$ of the vendace diet in this lake consisted of zooplankton. Whitefish had somewhat higher stomach fullness than vendace in the upstream lake, but only $\sim 20 \%$ of the stomach content was zooplankton. When zooplankton communities are depleted, pelagic whitefish may switch to zoobenthos (Næsje et al. 1991). Thus, while the specialist-feeder vendace appeared to be largely restricted to an obligatory zooplankton diet, the more generalist whitefish had switched to alternative food resources (zoobenthos and surface insects) in the upstream lake.

The conditions in the downstream lake were in strong contrast to the upstream lake. Downstream both vendace and whitefish had more than twice the stomach fullness recorded in the upstream lake and both species had almost exclusively zooplankton diets. The observed differences in feeding behavior between the two lakes were reflected in the diet overlap of the two fish species. In the downstream lake, where the impact of the invader was assumed to be insignificant, the diet overlap of vendace and whitefish was $86 \%$ in August and $88 \%$ in September. At this level of overlap the diets may be considered identical (Krebs 1989). In the upstream lake the diet overlap ranged from 27 to $52 \%$, which is considerably lower than in the downstream lake, and consequently demonstrate a diet segregation between the two species in the upper locality (cf. Fig. 8). Further, as the segregation seems to be forced upon the native whitefish by current competition from the invading vendace, the segregation in the upstream lake is interactive (cf. Nilsson 1967), and also asymmetric. In contrast to selective segregation, where species segregate in their resource utilization because of evolutionarily developed differences, interactive segregation is explained by present interspecific competition (Brian 
FIG. 8. Hypothetical niche curves for vendace and whitefish along a prey size-resource axis in situations with low and high food competition. The niche shift of whitefish shows that the interactive segregation is caused by asymmetric competition, vendace being the superior competitor.

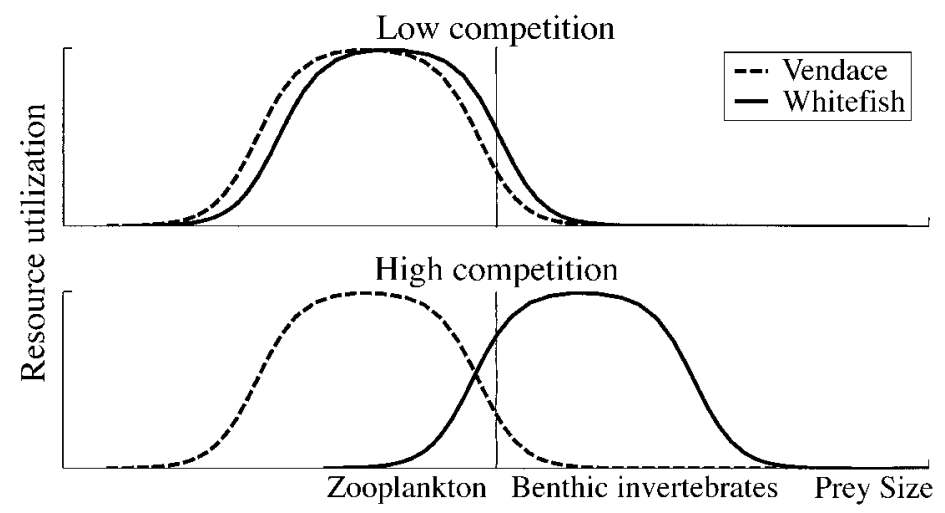

1956, Nilsson 1967 , Wootton 1990). If potentially competing species are distantly related, it may be difficult to distinguish if resource partitioning comes from taxonomic difference or from present interactions (Ross 1986). Interspecific competition should therefore preferably be studied in closely related species that use similar resources (Werner 1986). Support for interspecific competition is provided when two species have high overlap in resource utilization in allopatry and low overlap in sympatry (Nilsson 1967, Schoener 1970, Werner 1986). Further, limiting resources are a prerequisite for resource competition (Milne 1961, Werner 1986, Keddy 1989, Begon et al. 1996). The upstream lake of this study was clearly a sympatric situation where vendace and whitefish had coexisted in large numbers for at least three years. There were strong indications that the pelagic food resources in this lake were severely limited: (1) The specialized zooplanktivore vendace had a very low stomach fullness. (2) The prey community of zooplankton (species composition) was altered by the invading predator, especially during high temperatures in summer (reduced edible biomass and reduced size structure), probably due to temperature-correlated predation ( $\mathrm{B} \varnothing \mathrm{hn}$ and Amundsen 1998, cf. Gliwicz and Pijanowska 1989). (3) Vendace and whitefish segregated in feeding.

The downstream lake did not fulfil any of the listed indications of strong resource limitation as compared with the upstream lake, and the diet overlap between vendace and whitefish was very high. Consequently the impact from the invader seemed at this early phase of invasion to be insignificant. This is reasonable as the main interaction between the two coregonid species presumably is exploitative competition for zooplankton. Exploitative competition is an ecological process that needs time to have effect because the impact of the interaction has to develop via gradual resource depletion. Interference competition would, in contrast, be expected to have a more immediate effect as the dominant species may monopolize resources by antagonistic behavior (Keddy 1989, Begon et al. 1996). This is probably not likely to occur in the vendace-whitefish interrelation.
The competitive interaction between vendace and whitefish appears to be highly asymmetric, and the inter-lake diet-overlap analysis enables a quantification of this asymmetry: Which of the two species contributed most to the observed food segregation? The results are clear-cut; the whitefish diet exhibited large differences between the downstream and upstream lakes, changing from an almost exclusively zooplankton diet downstream to a dominance of zoobenthos in the upstream lake. The vendace diet was, on the other hand, fairly similar between the two sites, zooplankton being the dominant prey category. On average, the whitefish diet changed 34 percentage points (mean value of difference in inter-lake diet overlap between the two species in August and September, cf. Fig. 6) more than the diet of vendace between the upstream and downstream lakes. Hence, vendace was the competitively superior zooplankton specialist, excluding whitefish from the formerly overlapping parts of the resource axis. Stronger food specialization on zooplankton is generally connected with competitive dominance over other species (Svärdson 1976, Werner 1986), and the diet shift of whitefish in the upstream lake supports this hypothesis. The exclusion of zooplankton from the whitefish diet also appeared to be accompanied by a relegation of whitefish from the pelagic to the litoral and profundal habitats (Amundsen et al. 1999). Although whitefish were still caught in the pelagic zone in the upstream lake, their abundance has decreased considerably after the invasion of vendace (Amundsen et al. 1999). The ultimate consequence of the invasion may be a total elimination of whitefish from the pelagic habitat through competitive exclusion.

Most biological invasions fail (Moyle and Light 1996, Williamson and Fitter 1996), but those that do not, create opportunities to better understand what factors determine the ecological impacts of invasions (Orians 1986, Pimm 1989, Ross 1991). However, there is no unifying theory of biological invasions (Townsend 1996). The reason is probably that invasion biology embraces the full complexity of ecology in general, but only a few cases have been adequately studied. Predictive hypotheses and broad generalizations about bi- 
ological invasions are therefore hard to find (Simberloff 1986). Some studies, however, reveal a promising approach by combining detailed analyses of the invader and the receiving ecosystem (Orians 1986, Ehrlich 1989, Townsend 1996). From the present study, emphasizing both vendace as the invader and the Pasvik watercourse as the receiving ecosystem, five important theoretical aspects of invasions may be isolated:

Aspect 1) Arrival of the invader. Large body size generally reduces the risk of predation (e.g., Lawton and Brown 1986, Persson et al. 1996), and this may be particularly important when a small group of individuals of an exotic species arrives in a new area (cf. Crowell 1973, Ebenhard 1989). Vendace is generally a small-sized species, and this was also the case in the founder population in Lake Inari. The first immigrants may therefore have been highly vulnerable to predation by the high density of piscivorous predators (brown trout, pike, perch, and burbot) in the Pasvik watercourse. Interestingly, however, nine vendace individuals of exceptionally large sizes (264-307 mm fork length) were caught in the upstream part of the Pasvik watercourse in 1990 (Amundsen et al. 1999). The pioneer immigrants therefore appear to have been large sized, and this may have contributed to the successful establishment in the watercourse.

Aspect 2) Establishment and expansion. Phenotypic and life-history plasticity, or high genetic variability, are in general important for successful invasions of animals and plants (Bazzaz 1986, Ehrlich 1986). Strong plasticity is a common feature of freshwater fish (cf. Bruton 1986, Herbold and Moyle 1986, Townsend 1996), and vendace have shown considerable life-history plasticity over its short presence in Pasvik (Amundsen et al. 1999). The observed life-history changes include reduced somatic growth rates and earlier maturation, indicating a resource allocation towards an increased intrinsic rate of population increase and a more rapid life history, i.e., a typical pioneer strategy.

Aspect 3) Integration as a competitor to native species. A potential competitor may not become established in a community due to biotic resistance from native species (Elton 1958, Pimm 1989). For successful establishment, the invader must find either a biotic vacancy or a place weakly held by a displaceable species (Hobbs 1955). Fish invasions often result in resource segregation and coexistence (Orians 1986, Pen et al. 1992, Moyle 1999), but severe population decline or extinction of native species have also been documented (e.g., Zaret and Paine 1973, Herbold and Moyle 1986, Moyle et al. 1986, Kaufman 1992, Townsend 1996). For the invading vendace, the biotic resistance in Pasvik may have been considerable since the pelagic zone was occupied by high densities of the ecologically similar whitefish, but this seems to be have been overridden by the competitive superiority of vendace.

Introduced trophic generalists seem to cause larger community impacts compared to introduced trophic specialists (Ebenhard 1988). However, in Ebenhards paper, there are very few studies (five) of introduced specialists, but hundreds dealing with generalists. The evidence that introduced specialists give no ecological impact at all on the original community is therefore far from convincing (Pimm 1991). The vendace in Pasvik is clearly an example of the opposite. We believe that the effect of an invader depends on its trophic role: if an invading specialist confronts the niche of a native species, strong interactions must be expected. Further, if an invading specialist takes a keystone position in the food web, huge community consequences can be expected as well (see Aspects 4 and 5, below).

Aspect 4) The Pasvik River-a disturbed systemas a receiving community. Disturbances favor invading species (Elton 1958, Hobbs 1989, Pen et al. 1992), especially if the native species have had less previous experience of the disturbance compared to the invader (di Castri 1989). This was exactly the case for vendace in Pasvik. The watercourse has been altered by the construction of seven power stations. Most rapids and waterfalls have thereby been lost and replaced by lakes and reservoirs. These changes favor lake-dwelling species, and have most likely increased the possibility of vendace establishment and expansion in the watercourse.

Aspect 5) Community impacts. The community impacts of an exotic species depend on the trophic state of the community and the trophic role of the invader (Tailor et al. 1984, Vitousek 1990). In fish communities both top predators and zooplanktivore predators may have huge effects on the receiving communities (Moyle and Light 1996). Impacts through trophic cascades are further likely to occur if the invader significantly reduces the resources on the next trophic level down (Power 1992). In aquatic systems, pelagic communities of low diversity are especially vulnerable to cascades (Strong 1992). As a strong predator on zooplankton, vendace has proved capable of altering both the size and species composition of the zooplankton communities in the Pasvik watercourse (Bøhn and Amundsen 1998). The vendace invasion has also led to a relegation of the native pelagic whitefish to littoral and profundal habitats through interactive segregation and competition (Amundsen et al. 1999, this study). Further, vendace must be considered as a potential prey for a number of native piscivorous predators, including both fish (brown trout, pike, perch, and burbot) and birds (Gavia arctica, Mergus spp., Pandion haliaetus) (Bøhn et al., in press). Vendace thus already appear to have become a keystone species in the Pasvik watercourse, having potential consequences on all levels in the aquatic food chain, including primary producers (phytoplankton), primary consumers (zooplankton), secondary consumers (zooplanktivorous fish), and top predators (piscivorous fish and bird species). Relative to other subarctic freshwater systems, the Pasvik watercourse has a di- 
verse native fish fauna. The fish community may thus have been fairly well saturated compared to other fish communities in the region, although still unable to resist the vendace invasion. Hence, vendace have proven to have strong invasive and competitive abilities in a subarctic watercourse of relatively low productivity.

In conclusion, the observed differences between the upstream and downstream lakes demonstrate interactive food segregation between the invading specialist vendace and the more generalist native whitefish. Vendace and whitefish appear to have similar fundamental food niches, but segregate to different realized niches in sympatry-strong asymmetrical competition for food being the mechanistic force driving the segregation. The vendace has the upper hand in the competition, and the whitefish is relegated from the overlapping part of the food niche in sympatry (Fig. 8). Our study further demonstrates a successive process of competition and interactive segregation after the invasion of a competitive invader. The initial situation after the invasion is high dietary overlap, but low competition due to a low density of the invader. Later, as the density of the invader increases, competition increases correspondingly. Intensified competition results in increased resource limitation in the pelagic zooplankton and initiation of interactive segregation. This gradually leads to a reduced niche overlap, thereby alleviating the impacts of the competitive interactions between the individuals of the two species. It should, however, be stressed that competition is still active and strong despite the segregation and low overlap between the species. Consequently, a hypothetical removal of the invader would presumably lead to a competitive release of the native species, i.e., the whitefish would return to its original pelagic niche after removal of vendace. But the invasion of vendace is probably an irreversible process, as most "successful" invasions are, and the ecological consequences in the watercourse are likely to proceed and even intensify in the future.

\section{ACKNOWLEDGMENTS}

We wish to thank Malcolm Elliott and Odd Terje Sandlund for valuable comments on earlier drafts of the manuscript, and Frode Staldvik, Laina Dalsb $\varnothing$, Jan Evjen, Raul Primicerio, Elleke Wartena, Bjørn Hermansen, and Vegard Steiro Amundsen for help during field and laboratory work. Financial support was given by the Norwegian Research Council under the program "Biological Diversity-Dynamics, Threats and Management," the Directorate for Nature Management, and the Governor of Finnmark County.

\section{Literature Cited}

Amundsen, P.-A. 1988. Habitat and food segregation of two sympatric populations of whitefish (Coregonus lavaretus L. s.1.) in Stuorajavri, northern Norway. Nordic Journal of Freshwater Research 64:67-73.

Amundsen, P.-A., F. J. Staldvik, Y. S. Reshetnikov, N. Kashulin, A. Lukin, T. Bøhn, O. T. Sandlund, O. Popova. 1999. Invasion of vendace Coregonus albula in a subarctic watercourse. Biological. Conservation. 88:405-413.

Auvinen, H. 1988. Factors affecting the year-class strength of vendace (Coregonus albula) in lake Pyhäjärvi (Karelia, SE-Finland). Finnish Fisheries Research 9:235-243.

Bazzaz, F. A. 1986. Life history of colonizing plants: some demographic, genetic, and physiologic features. Pages 96110 in H. A. mooney and J. A. Drake, editors. Ecology of biological Invasions of North America and Hawaii. Springer-Verlag, New York, New York, USA.

Begon, M., Harper, J. L., and C. R. Townsend. 1996. Ecology. Individuals, populations and communities. Third edition. Blackwell Science, London, UK.

Bøhn, T., and P.-A. Amundsen. 1998. Effects of invading vendace (Coregonus albula $\mathrm{L}$.) on species composition and body size in two zooplankton communities of the Pasvik River system, Northern Norway. Journal Plankton Research 20:243-256.

Bøhn, T., P.-A. Amundsen, O. Popova, Y. S. Reshetnikov, and F. Staldvik. In press. Predator avoidance of coregonids: Habitat choice explained by size-related prey vulnerability? Archiv für Hydrobiologie.

Bottrell, H. H., A. Duncan, Z. M. Gliwicz, E. Grigorieck, A. Herzig, A. Hillbricht-Ilkowska, H. Kurasawa, P. Larsson, and T. Weglenska. 1976. A review of some problems in zooplankton production studies. Norwegian Journal of Zoology 24:419-456.

Brian, M. V. 1956. Segregation of species of the ant genus Myrmica. Journal of Animal Ecology 25:319-337.

Bruton, M. N. 1986. Life history stages of invasive fishes in Southern Africa. Pages 47-62 in I. A. W. Macdonald, F. J. Kruger, and A. A. Ferrar, ediltors. The ecology and management of biological invasions in Southern Africa. A. A. Balkema, Cape Town, South Africa.

Carpenter, S. R., J. K. Kitchell, and J. R. Hodgson, 1985. Cascading trophic interactions and lake productivity. BioScience 35:634-639.

Christensen, G. N. 1994. Selektiv predasjon hos pelagisk røye, Salvelinus alpinus (L.) i Skogsfjordvannet, en oligotrofisk innsjø i Nord-Norge. [In Norwegian.] Thesis. Norwegian College of Fisheries Science, University of Troms $\varnothing$, Troms $\varnothing$, Norway.

Crowell, K. L. 1973. Experimantal zoogeography: introductions of mice to small islands. American Naturalist 107: 535-58.

di Castri, F. 1989. History of biological invasions with special emphasis on the old world. Pages 315-29 in J. A. Drake, H. A. Mooney, F. di Castri, R. H. Groves, F. J. Kruger, M. Rejmanek, and M. Williamson, editors. Biological invasions: a global perspective. John Wiley and Sons, New York, New York, USA.

Ebenhard, T. 1988. Introduced birds and mammals and their ecological effects. Swedish Wildlife Research 13:1-107.

Ebenhard, T. 1989. Bank vole Clethrionomys glareolus Schreber 1780. Propagules of different sizes and island colonization. Journal of Biogeography 16:173-180.

Ehrlich, P. R. 1986. Which animal will invade? Pages 7995 in H. A. Mooney and J. A. Drake, editors. Ecology of biological invasions of North America and Hawaii. Springer-Verlag, New York, New York, USA.

Ehrlich, P. R. 1989. Attributes of invaders and the invading process: vertebrates. Pages 315-329 in J. A. Drake, H. A. Mooney, F. di Castri, R. H. Groves, F. J. Kruger, M. Rejmanek, and M. Williamson, editors. Biological invasions: a global perspective. John Wiley \& Sons, New York, New York, USA.

Elton, C. S. 1958. The ecology of invasion by animals and plants. John Wiley \& Sons, New York, New York, USA. Evans, D. O., B. A. Henderson, N. J. Bax, T. R. Marshall, R. T. Oglesby, and W. J. Christie. 1987. Concepts and methods of community ecology applied to freshwater fisheries management. Canadian Journal of Fisheries and Aquatic Sciences 44:448-470. 
Gause, G. F. 1934. The struggle for existence. Haefner, New York, New York, USA.

Giller, P. S. 1984. Community structure and the niche. Chapman \& Hall, New York, New York, USA.

Gliwicz, M., and J. Pijanowska. 1989. The role of predation in zooplankton succession. Pages 253-296 in U. Sommer, editor. Plankton ecology: succession in plankton communities. Springer-Verlag, Berlin, Germany.

Hamrin, S. F. 1983. The food preferance of vendace (Coregonus albula) in South Swedish forest lakes including the predation effect on zooplankton populations. Hydrobiologia 101:121-128.

Hamrin, S. F., and L. Persson. 1986. Asymmetrical competition between age classes as a factor causing population oscillations in an obligate planktivorous fish species. Oikos 47:223-232.

Hardin, G. 1960. The competitive exclusion principle. Science 131:1292-1297.

Helminen, H., and A. Sarvala. 1994. Population regulation of vendace (Coregonus albula) in Lake Pyhäjärvi, Southwest Finland. Journal of Fish Biology 45:387-400.

Herbold, B., and P. B. Moyle. 1986. Introduced species and vacant niches. American Naturalist 128:751-760.

Hobbs, D. F. 1955. Do newly introduced species present a separate problem? Proceedings of The New Zealand Ecological Society 2:12-14.

Hobbs, R. J. 1989. The nature and effects of disturbance relative to invasions. Pages 389-405 in J. A. Drake, H. A. Mooney, F. di Castri, R. H. Groves, F. J. Kruger, M. Rejmanek, and M. Williamson, editors. Biological invasions: a global perspective. John Wiley \& Sons, New York, New York, USA.

Kankaala, P., A. Vasama, K. Eskonen, and L. Hyytinen, 1990. Zooplankton of Lake Ala-Kitka (NE-Finland) in relation to phytoplankton and predation by vendace (Coregonus albula). Aqua Fennica 20:81-94.

Kaufmann, L. 1992. Catastrophic change in species-rich freshwater ecosystems: the lessons of Lake Victoria. BioScience 42:846-858.

Keddy, P. A. 1989. Competition. Chapman \& Hall, London, UK.

Krebs, C. J. 1989. Niche overlap and diet analysis. Pages 371-398 in Ecological methodology. Harper Collins College Publishers, New York, New York, USA.

Langeland, A. 1982. Interactions between zooplankton and fish in a fertilized lake. Holarctic Ecology 5:273-310.

Langeland, A., editor. 1993. Pollution impact on freshwater communities in the border region between Russia and Norway. II. Baseline study 1990-1992. NINA scientific report 44. Norwegian Institute for Nature Research, Trondheim, Norway.

Lawton, J. H., and K. C. Brown. 1986. The population and community ecology of invading insects. Philosophical Transactions of the Royal Society of London 314:607-617.

Levins, R. 1968. Evolution in changing environments. Princeton University Press, Princeton, New Jersey, USA.

McQueen, D. J., M. R. S. Johannes, J. R. Post, T. J. Steward, and D. R. S. Lean. 1989. Bottom-up and top-down impacts on freshwater pelagic community structure. Ecological Mongraphs 59:289-309.

Milne, A. 1961. Definition of competition among animals. Symposia of the Society for Experimental Biology 15:4061.

Moyle, P. B. 1999. Effects of invading species on freshwater and estuarine ecosystems. Pages 177-191 in Invasive species and biodiversity management. O. T. Sandlund P. J. Schei, and A. Viken, editors. Kluwer Academic, Dordrecht, The Netherlands.

Moyle, P. B., H. W. Li, and B. A. Barton. 1986. The Frankenstein effect: impact of introduced fishes on native fishes in North America. Pages 415-426 in R. H. Shroud, editor. Fish culture in fisheries managements. American Fisheries Society, Bethesda, Maryland, USA.

Moyle, P. B., and T. Light. 1996. Biological invasions of fresh water: empirical rules and assembly theory. Biological Conservation 78:149-162.

Mutenia, A., and M. Ahonen. 1990. Recent changes in the fishery on Lake Inari, Finland. Pages 101-111 in W. L. T. van Densen, B. Steinmetz, and R. H. Hughes, editors. Management of freshwater fisheries. Centre for Agricultural Publishing and Documentation, Wageningen, The Netherlands.

Mutenia, A., and E. Salonen. 1992. The vendace (Coregonus albula L.), a new species in the fish community and fisheries of Lake Inari. Polish Archives of Hydrobiology 39:797805.

Næsje, T. F., B. Jonsson, O. T. Sandlund, and G. Kjellberg. 1991. Habitat switch and niche overlap in coregonid fishes: effects of zooplankton abundance. Canadian Journal of Fisheries and Aquatic Sciences 48:2307-2315.

Nilsson, N.-A. 1967. Interactive segregation between fish species. Pages 295-313 in S. D. Gerking, editor. The biological basis of freshwater fish production. Blackwell, Oxford, UK.

Orians, G. H. 1986. Site characteristics favouring invasions. Pages 133-148 in H. A. Mooney and J. A. Drake, editors. Ecology of biological invasions of North America and Hawaii, Springer-Verlag, New York, New York, USA.

Pen, L. J., I. C. Potter, and M. C. Calver. 1992. Comparisons of the food niches of three native and two introduced species in an Australian river. Environmental Biology of Fishes 36:167-182.

Persson, L., J. Andersson, E. Wahlstrom, and P. Eklov. 1996. Size-specific interactions in lake systems: predator gape limitation and prey growth rate and mortality. Ecology 77: 900-911.

Pimm, S. L. 1989. Theories of predicting success and impact of introduced species. Pages 351-367 in J. A. Drake, editor. Biological invasion: a global perspective. John Wiley \& Sons, New York, New York, USA.

Pimm, S. L. 1991. The balance of nature? Ecological issues in the conservarion of species and communities. University of Chicago Press, Chicago, Illinois, USA.

Power, M. E. 1992. Top-down and bottom-up forces in food webs: Do plants have primacy? Ecology 73:733-746.

Reshetnikov, Y. S. 1980. Ecology and systematics of Coregonid fish. [In Russian]. Nauka, Moscow, Russia.

Ross, S. T. 1986. Resource partitioning in fish assemblages: a review of field studies. Copeia 2:352-388.

Ross, S. T. 1991. Mechanisms structuring stream fish assemblages: Are there lessons from introduced species? Environmental Biology of Fishes 30:359-368.

Rudstam, L. G., R. C. Lathrop, and S. R. Carpenter. 1993. The rise and fall of a dominant planktivore: direct and indirect effects on zooplankton. Ecology 42:303-319.

Sandlund, O. T., B. Jonsson, T. F. Næsje, and P. Aass. 1991. Year-class fluctuations in vendace (Coregonus albula): Who's got the upper hand in intraspecific competiton? Journal of Fish Biology 38:873-885.

Schindler, D. W. 1969. Two useful devices for vertical plankton and water sampling. Journal of the Fisheries Research Board of Canada 26:1948-1955.

Schoener, T. W. 1970. Nonsynchronous spatial overlap of lizards in patchy habitats. Ecology 51:408-418.

Schoener, T. W. 1974. Resource partitioning in ecological communities. Science 185:27-39.

Schoener, T. W. 1986. Resource partitioning. Pages 91-126 in J. Kikkawa and D. J. Anderson, editors. Community ecology. Blackwell Scientific, Oxford, UK.

Shapiro, J. 1980. The importance of trophic-level interactions 
to the abundance and species composition of algae in lakes. Pages 105-116 in J. Barica and L. R. Mur, editors. Hypertrophic ecosystems. Dr W. Junk, The Hague, The Netherlands.

Simberloff, D. 1981. Community effects of introduced species. Pages 53-81 in M. H. Nitecki, editor. Biotic crisis in ecological and evolutionary time. Academic Press, New York, New York, USA.

Simberloff, D. 1986. Introduced insects: a biogeographic and systematic perspective. Pages 3-26 in H. A. Mooney and J. A. Drake, editors. Ecology of biological invasions of North America and Hawaii. Springer-Verlag, New York, New York, USA

Strong, D. R. 1992. Are trophic cascades all wet? Differeniation and donor-control in speciose ecosystems. Ecology 73:747-754.

Svärdson, G. 1957. The Coregonid problem. VI. The Palearctic species. Institute of Freshwater Research Drottningholm, Report 38:267-356.

Svärdson, G. 1976. Interspecific population dominance in fish communities in Scandinavian lakes. Institute of Freshwater Research Drottningholm, Report 55:144-171.

Svärdson, G. 1979. Speciation of Scandinavian Coregonus. Institute of Freshwater Research Drottningholm, Report 57: $1-95$.

Tailor, J. N., W. R. Cortenay, and J. A. McCann. 1984. Known impacts of exotic fishes in the continental United States. Pages 322-373 in W. R. Cortenay and J. R. Stauffer, Jr., editors. Distribution, biology and management of exotic fishes. Johns Hopkins University Press, Baltimore, Maryland, USA.
Townsend, C. R. 1996. Invasion biology and ecological impacts of brown trout Salmo trutta in New Zealand. Biological Conservation 78:13-22.

Viljanen, M. 1983. Food and food selection of cisco (Coregonus albula L.) in a dysoligotrophic lake. Hydrobiologia 101:129-138.

Vitousek, P. M. 1990. Biological invasions and ecosystem processes: towards an integration of population biology and ecosystem studies. Oikos 57:7-13.

Wallace, R. K. 1981. An assessment of diet-overlap indexes. Transactions of the American Fisheries Society 110:72-76.

Werner, E. E. 1984. The mechanisms of species interactions and community organization in fish. Pages 360-382 in D. R. J. Strong, D. Simberloff, L. G. Abel, and A. B. Thistle, editors. Ecological communities. Princeton University Press, Princeton, New Jersey, USA.

Werner, E. E. 1986. Species interactions in freshwater fish communities. Pages 344-357 in J. Diamond and T. J. Case, editors. Community ecology. Princeton University Press, Princeton, New Jersey, USA.

Williamson, M., and A. Fitter, 1996. The varying success of invaders. Ecology 77:1661-1666.

Wootton, R. J. 1990. Ecology of teleost fishes. Chapman \& Hall, New York, New York, USA.

WRI/IUCN/UNEP 1992. [World Resources Institute, The World Conservation Union, and United Nations Environment Programme]. Global biodiversity strategy. World Resources Institute, Washington, D.C., USA.

Zaret, T. M., and R. T. Paine. 1973. Species introduction in a tropical lake. Science 182:449-455. 